Revista Monografias Ambientais

Santa Maria, Edição Especial Curso de Especialização em Educação Ambien-

tal. 2015, p. 17-25

Revista do Centro de Ciências Naturais e Exatas - UFSM

\title{
A Logística Reversa à Serviço do Desenvolvimento Sustentável e o Papel da Escola com Relação à Educação Ambiental
}

\section{The Reverse Logistics at Service to Sustainable Development and the Role of The School Con- cerning the Environmental Education}

\author{
Lucas Juarez Hempe ${ }^{1}$, Cléa Hempe ${ }^{2}$
}

\author{
${ }^{1}$ Bacharel em Administração, com linha de formação específica em Comércio Exterior pela Faculdade SENAC-PE, Aluno do \\ Curso de Pós-Graduação MBA em Gestão de Pessoas nas Organizações pela FOCCA - Faculdade de Olinda-PE - Brasil - \\ lhempe@gmail.com \\ ${ }^{2}$ Graduada em Geografia pela UNIJUI (RS), Especialista em Gestão e Apoio Pedagógico na Educação Básica -UNICRUZ- (RS), \\ Especialista em Mídias na Educação -UFSM- (RS), Mestra em Geografia - UFSM- (RS), Tutora do Curso de Especialização em \\ Educação Ambiental/Polo Presencial de Panambi(RS) , Professora de Geografia lotada no Museu e Arquivo Histórico Professor \\ Hermann Wegermann Panambi (RS). \\ cleahempe@hotmail.com
}

Resumo

A logística reversa é um tema que pode ser abordado na Educação Ambiental, em qualquer série/ano da Educação Básica. As escolas desempenham um papel importante em prol do Meio Ambiente, pois não mobilizam apenas os alunos, mas também seus familiares e toda a comunidade a desenvolver novos hábitos. Do mesmo modo, também contribuem para o cumprimento da Lei, a qual traz a responsabilidade compartilhada entre todos os geradores de resíduos da cadeia produtiva: fabricantes, comerciantes e cidadãos. O objetivo geral deste artigo foi apresentar ao leitor, por meio de um resgate de como sucedeu o surgimento desta ferramenta ambiental, a logística reversa, apresentando exemplos de sua aplicabilidade nos mais diversos setores, bem como as vantagens obtidas pelas organizações ao agregar esta ferramenta ao seu sistema de gestão ambiental. A logística reversa trata-se de um recurso estratégico, à disposição das organizações, voltado para o desenvolvimento sustentável. Esta visa à obtenção de vantagens competitivas através da melhoria dos processos produtivos das organizações, aliadas à implantação de um sistema de gestão ambiental. Do mesmo modo, tem a missão de proporcionar um crescimento sustentável, exercendo um papel muito mais amplo do que simplesmente auxiliar no cumprimento da legislação ambiental vigente. A metodologia utilizada foi a pesquisa bibliográfica. O presente artigo visa possibilitar ao leitor uma reflexão acerca da importância da logística reversa para o desenvolvimento sustentável das organizações e como sugestão de tema para ser discutido e abordado por professores e alunos no cotidiano escolar.

Palavras-Chave: Logística reversa. Sustentabilidade. Meio Ambiente. Educação Ambiental. Escola.

Abstract

The reverse logistics is an issue that can be approached in the Environmental Education, in any series/year of Basic Education. Schools play an important role towards the environment; they do not only mobilize the students, but also their families and the community to develop new habits. Similarly, they also contribute to the fulfillment of the regulations, which brings the shared responsibility of all waste generators in the production chain: manufacturers, merchants and citizens. The aim of this paper was to present to the reader, by means of a rescue, the way on how has arisen this environmental tool, the reverse logistics, showing examples of its applicability on many different sectors, as well as the advantages obtained by the organizations in adding this tool to its environmental management system. The reverse logistics it is a strategic resource to the organizations, focused on the sustainable development. It aims to obtain competitive advantages by streamlining the production processes of the organizations, along with the implementation of an environmental management system. Similarly, it has the mission to provide sustainable growth, playing a much broader role than simply assist in compliance with the current environmental legislation. The methodology used was the bibliographic research. This article aims to enable the reader to reflect on the importance of the reverse logistics for the sustainable development of the organizations and as a matter of suggestion to be discussed and approached by teachers and students in daily school life.

Keywords: Reverse logistics. Sustainability. Environment. Environmental Education. School. 


\section{Introdução}

$\mathrm{Na}$ atualidade, os municípios através dos Conselhos Municipais do Meio Ambiente e das Secretarias Municipais de Educação tem buscado parcerias com as empresas para discutir temas relacionados ao Meio Ambiente. As empresas por sua vez colaboram financeiramente para a realização de congressos regionais, nacionais, internacionais, oportunizando à muitos acadêmicos divulgar estudos realizados e relacionados ao meio ambiente, sustentabilidade, legislação, entre outros temas. Este artigo apresenta um estudo sobre o tema logística reversa.

$\mathrm{O}$ avanço tecnológico industrial resultou em uma expressiva alavancagem dos processos de produção e consumo de bens e serviços. Atualmente há uma gama enorme de eletroeletrônicos dos mais variados, como tocadores de áudio digital, celulares, tablets, notebooks, etc. Isto, por sua vez, acarretou no aumento dos descartes e em uma velocidade espantosa, pois, em um pequeno espaço de tempo o consumidor se desfaz de um produto e compra outro recém-lançado no mercado.

O consumidor pode se desfazer de um produto pelo simples desejo de comprar outro, ou ainda por necessidade. Quando se trata de uma necessidade, possivelmente ocorrerá devido ao seu desgaste natural, ou por problemas técnicos que inviabilizem o seu conserto. Infelizmente, na maioria das vezes, este descarte é realizado sem os devidos cuidados, podendo acarretar sérios danos ao meio ambiente e consequentemente à população que dele usufrui.

O governo está atento a estes problemas ocasionados pelo progresso e pelo consumo acelerado, ou ainda, muitas vezes desenfreado da sociedade moderna. Os órgãos competentes perceberam que havia a necessidade de estabelecer regras de conduta e de criar mecanismos que permitissem o manejo correto dos produtos e materiais após o seu consumo. Sejam estes, inservíveis ou que ainda podem ser reutilizados, retornando para o processo produtivo.

A partir desta nova demanda surgiu a logística reversa, uma ferramenta que visa auxiliar os gestores na gestão dos Sistemas de Gestão Ambiental (SGA). Sendo estes, implementados pelas organizações com a finalidade de administrar as questões envolvendo suas políticas socioambientais.

A logística reversa dispõe-se a operacionalizar o retorno dos diversos resíduos produzidos após a sua geração, direcionando-os para o seu ponto de partida, a fim de realizar o descarte definitivo ou se possível, dependendo do tipo de material, reciclar estes resíduos e reaproveitá-los para outro fim.

Este artigo resgata a história da logística reversa, uma ferramenta ambiental extremamente importante para as organizações. Também são apresentadas as vantagens econômicas, os benefícios ambientais e sociais proporcionados pela sua adoção. Por fim, são expostas campanhas e projetos adotados por empresas e escolas com a finalidade de usufruir dos benefícios da logística reversa com vistas à sustentabilidade do planeta.

\section{Referencial teórico}

\subsection{Sustentabilidade}

O conceito de sustentabilidade e os critérios que definem atualmente determinadas práticas como sendo sustentáveis começaram a tomar forma a partir de uma Conferência das Nações Unidas para o Meio Ambiente Humano, realizada na cidade de Estocolmo - Suécia, no ano de 1972. A conferência foi realizada para discutir os problemas ambientais relacionados ao desenvolvimento econômico. A partir das discussões, podem-se criar alternativas que pudessem promover o desenvolvimento econômico, ao mesmo tempo em que fossem adotadas formas de manejo que permitissem a preservação do meio ambiente (GUARNIERI, 2011).

No ano de 1987 em uma publicação de um relatório desenvolvido pela Comissão Mundial sobre o Meio Ambiente e Desenvolvimento (CMMAD), o conceito de desenvolvimento sustentável foi utilizado pela primeira vez. A partir deste momento as organizações também começaram a desenvolver alternativas que pudessem promover a produção sustentável. Assim, as discussões acerca do tema no ambiente dos negócios passaram a ser constantes entre as organiza- 
ções. Pois, perceberam que as adoções de tais práticas eram importantes para a imagem da corporação perante o mercado e seus clientes (GUARNIERI, 2011).

Segundo Bellen (2005, p.23) "sustentabilidade é o emprego de tecnologia e de organização social, atendendo a necessidade das gerações presentes sem comprometer a possibilidade das gerações futuras atenderem as suas próprias necessidades". Para a Comissão Mundial sobre o Meio Ambiente e Desenvolvimento (1987), desenvolvimento sustentável "é a capacidade de prover o crescimento e suprir as necessidades da geração presente sem afetar a habilidade das gerações futuras".

Giordano (2003, p. 317) coloca a abrangência dessa visão:

\begin{abstract}
O mais interessante de tudo é que não se abordará apenas produtos, mas sistemas de produção ambientalmente corretos. Tratar-se-á de outro fenômeno ocorrido nos últimos dez anos que foi a transição do foco apenas no meio ambiente para um foco mais abrangente, mais subjetivo e mais complicado, do qual o meio ambiente faz parte, chamado sustentabilidade. Para muitos consumidores não basta apenas o produto ser "verde". O modo de produção deve ser sustentável.
\end{abstract}

Portanto, pode-se afirmar que a sustentabilidade no meio empresarial visa o fornecimento de produtos ou serviços, que atendam as necessidades dos seus clientes e que lhes deem o retorno financeiro esperado. Porém, sem comprometer o meio ambiente, extraindo apenas os recursos naturais necessários à sua operação, respeitando a capacidade e tempo de reposição destes recursos naturais. Ou ainda, buscando fontes alternativas, adotando o uso de recursos renováveis, que possam ser utilizados na fabricação de seus produtos.

\title{
2.2 Logística reversa
}

Na visão de Leite (2003, p. 16) a logística reversa trata-se de:

Área da logística empresarial que planeja, opera e controla o fluxo e as informações logísticas correspondentes, do retorno dos bens de pós-venda e pós-consumo ao ciclo de negócios ou ao ciclo produtivo, por meio dos canais de distribuição reversos, agregandolhes valor de diversas naturezas: econômico, ecológico, de imagem corporativa, entre outros.

De acordo com a Política Nacional de Resíduos Sólidos (PNRS, Lei $\mathrm{n}^{\circ}$. 12.305/2010), a logística reversa é entendida como:

Instrumento de desenvolvimento econômico e social caracterizado por um conjunto de ações, procedimentos e meios destinados a viabilizar a coleta e a restituição dos resíduos sólidos ao setor empresarial, para reaproveitamento, em seu ciclo ou em outros ciclos produtivos, ou outra destinação final ambientalmente adequada.

Em síntese, a logística reversa é uma ferramenta estratégica que bem explorada pelas organizações, auxiliará na preservação do meio ambiente, contribuirá para o desenvolvimento econômico e social, além de agregar valor à imagem corporativa (VALLE; SOUZA, 2014). Após os produtos/materiais serem descartados e coletados, passam pelos canais de distribuição reversa. Nesta fase os produtos/materiais são divididos de acordo com seu tipo e condição, e isto que irá determinar o canal (Figura 1) que irá recebê-lo. Há um canal para produtos recondicionados, para materiais que podem ser reciclados, revendidos ou ainda um canal específico para os produtos que precisam ser descartados em aterros sanitários específicos.

Figura 1 - Canais de distribuição reversos 


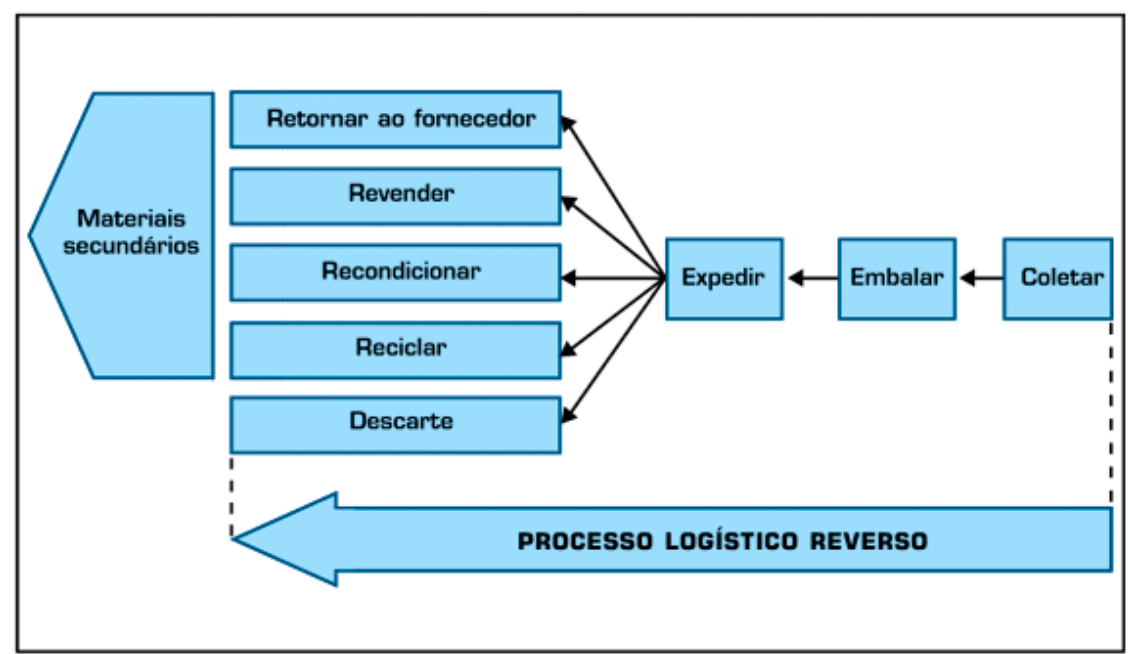

Fonte: Adaptado de Rogers \& Tibben-Lembke (1999).

\subsubsection{Logística reversa da pós-venda $X$ logística reversa do pós-consumo}

Conforme Leite (2003), a logística reversa atua em duas grandes áreas: bens de pós-venda e a dos bens de pós-consumo, além de um grupo de resíduos industriais (Figura 2).

Figura 2 - Áreas da logística reversa

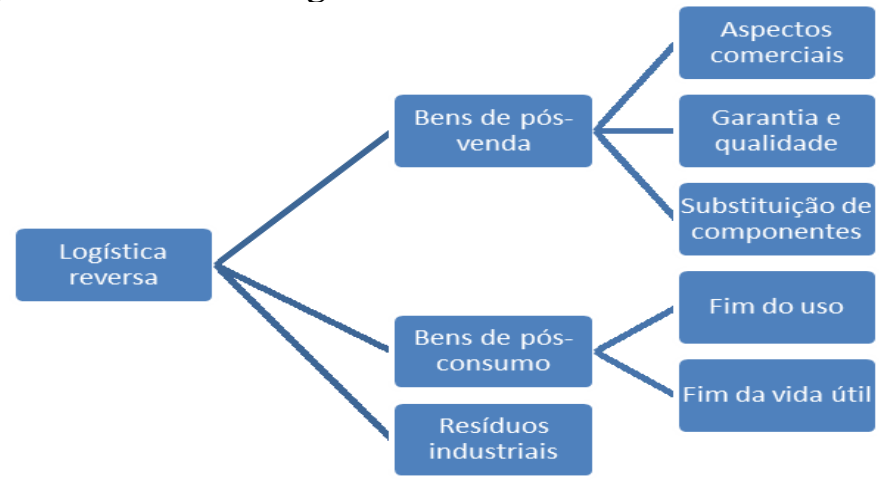

Fonte: Adaptado de Leite (2003).

De acordo com Valle (2014), os bens de pós-venda podem ser oriundos de situações relacionadas aos aspectos comerciais, como um produto enviado incorretamente, uma mercadoria em consignação, um material com prazo de validade vencido ou que esteja obsoleto. Também retornam por aspectos de garantia e qualidade, nos casos dos produtos danificados durante o processo de distribuição, que apresentaram defeito de fabricação, ou ainda provenientes de um processo de recall do fabricante.

Há ainda os bens que retornam a partir da substituição de componentes de bens duráveis ou semiduráveis (componentes substituídos durante a manutenção de um produto/equipamento). Por fim, apresenta-se o grupo dos resíduos industriais, alguns destes resíduos são tratados e posteriormente reutilizados dentro da mesma empresa. Podem também serem comercializado para outras empresas utilizarem em seus processos produtivos, e por sua vez, os resíduos que não podem ser reaproveitados/reciclados são destinados aos aterros sanitários.

\subsubsection{Benefícios da logística reversa}

A logística reversa proporciona vantagens do ponto de vista econômico, ambiental e social. Mesmo havendo a necessidade de grandes investimentos, se bem implementada, o retorno do investimento ocorrerá a médio e longo prazo. Do ponto de vista econômico, seria possível atribu- 
ir novamente um valor de mercado a um grande número de produtos que atualmente são descartados, simplesmente enviados a um aterro sanitário. Há a possibilidade de revenda para o mercado primário (servindo de matéria-prima), venda no mercado secundário, ser comercializado para um desmanche, para uma empresa de remanufatura ou de reciclagem (TADEU et al., 2013).

Segundo Guarnieri (2011) a adoção de embalagens retornáveis pode diminuir os custos que existiriam com a aquisição de novas embalagens. Como exemplos de itens de reuso direto, podem ser citados os paletes, contêineres e as garrafas. A comercialização de resíduos para o mercado secundário também pode ser uma ótima fonte de renda, utilizando-se da reciclagem também seria possível amortizar os custos de coleta e processamento. A autora ainda destaca que grande parte das empresas desconhece o potencial de retorno financeiro e econômico que a logística reversa pode oferecer.

Em inúmeros casos, os gestores desconhecem inclusive os volumes de resíduos gerados pelas suas organizações, deixando desta forma, de gerenciá-los de maneira que pudessem agregar novamente algum valor. Por outro lado, Xavier e Corrêa (2013) apontam que esta realidade já faz parte do passado para outras organizações. Há empresas que ao decidirem em investir e incorporar negócios ambientalmente sustentáveis aos seus processos, obtiveram um retorno (aumento do valor de mercado) positivo para sua marca perante o mercado consumidor.

A empresa PepsiCo, uma das maiores empresas do mundo no segmento de alimentos e bebidas, possui um programa chamado Programa Reciclo PepsiCo. Este programa foi criado para promover ações que proporcionem a redução de materiais em suas linhas de produção (como o plástico e tinta em embalagens de snacks) e estimule a reutilização de materiais. Atualmente são utilizadas as embalagens pós-consumo recicladas, como um dos principais insumos para a fabricação de displays. Foram mais de 92 mil displays produzidos em três anos, com quase 500 toneladas de embalagens reutilizadas (PEPSICO, 2013).

Em relação às vantagens ambientais proporcionados pelo uso da logística reversa, Guarnieri (2011) afirma que a sua adoção permite diminuir o desperdício e a poluição com relação aos materiais de embalagens. Ao empregar estas novas técnicas as organizações poderão reciclar, reutilizar embalagens/produtos. Outra opção seria substituir materiais poluentes ao meio ambiente, atualmente utilizados em sua produção, por materiais alternativos, preferencialmente os oriundos de fontes renováveis.

O fato das organizações mostrarem preocupação com a preservação do meio ambiente, e colocarem em prática projetos voltados a este fim, para Guarnieri (2011), proporcionará um ganho enorme para toda a sociedade. Pois a postura adotada, irá contribuir para a preservação do meio ambiente, permitindo que as gerações futuras possam usufruir de seus benefícios.

De acordo com a publicação da Revista Vidro \& Alumínio, parte da matéria-prima utilizada pela indústria de fabricação de vidros é proveniente de material reciclado. Um exemplo citado é o da empresa Saint-Gobain Glass, que adotou o uso de cacos de vidro automotivo para fabricar seus produtos. Este tipo de vidro pode corresponder até a $80 \%$ do total de vidros reciclados utilizados pela organização (REVISTA VIDRO \& ALUMÍNIO, 2014).

Segundo a matéria da Revista Vidro \& Alumínio, ao adotar o uso de material reciclado, a empresa Saint-Gobain Glass estará contribuindo significativamente para o meio ambiente. Pois haverá menor extração de matéria-prima natural (areia, sulfato, barrilha, feldspato e calcário) para fabricação dos produtos que são compostos de vidro. A economia de energia é outro fator positivo, será em torno de $30 \%$, dependo da proporção de cacos de vidros utilizados. Por fim, o vidro produzido a partir do vidro reciclado pode reduzir a poluição da água em $50 \%$ e do ar em 20\% (REVISTA VIDRO \& ALUMÍNIO, 2014).

Ao adotar a logística reversa, a organização também estará realizando uma grande contribuição sob o ponto de vista social. Pois, a cadeia produtiva reversa gera inúmeros empregos, seja por meio das associações e cooperativas de catadores ou ainda através das empresas recicladoras especializadas que atuam na segregação, pré-processamento e processamento dos materiais (XAVIER; CORRÊA, 2013).

A Coca-Cola é uma entre as diversas empresas que promovem projetos sustentáveis. $\mathrm{O}$ exemplo pôde ser vivenciado na Copa do Mundo onde foram instalados Polos de Reciclagem nas 12 cidades-sede. Segundo a empresa, o objetivo foi gerar renda aos trabalhadores, oferecer dignidade e segurança. Também gerar a valorização dos materiais recicláveis, incentivando toda a cadeia de reciclagem no Brasil (COCA-COLA, 2014). 
Ainda segundo a Coca-Cola, os Polos de Reciclagem criados permitirão a triagem de pelo menos 1.800 toneladas de materiais recicláveis por ano. Este número é três vezes maior do que a média da maioria das centrais de reciclagem. Sendo que a renda dos catadores também poderá triplicar, podendo chegar até a $\mathrm{R} \$ 2.000,00$ (mês) por pessoa. Especificamente para o evento da Copa do Mundo no Brasil, foram capacitados 840 catadores para atuarem nas 12 cidades-sede. Ao final do evento, após 64 jogos realizados, foram obtidas 416 toneladas em materiais reciclados.

De acordo com os dados da Associação Brasileira de Empresas de Limpeza Pública e Resíduos Especiais (ABRELPE), somente o mercado de limpeza urbana movimentou considerável volume de recursos. No ano de 2013 ultrapassou a casa dos 24 bilhões de reais, demonstrando desta forma, a sua relevância no cenário econômico do país. A seguir (Figura 3), apresenta-se o número de empregos diretos gerados pelo setor de limpeza urbana nas regiões e no país como um todo.

Figura 3 - Empregos Diretos Gerados pelo Setor de Limpeza Urbana - Regiões e Brasil

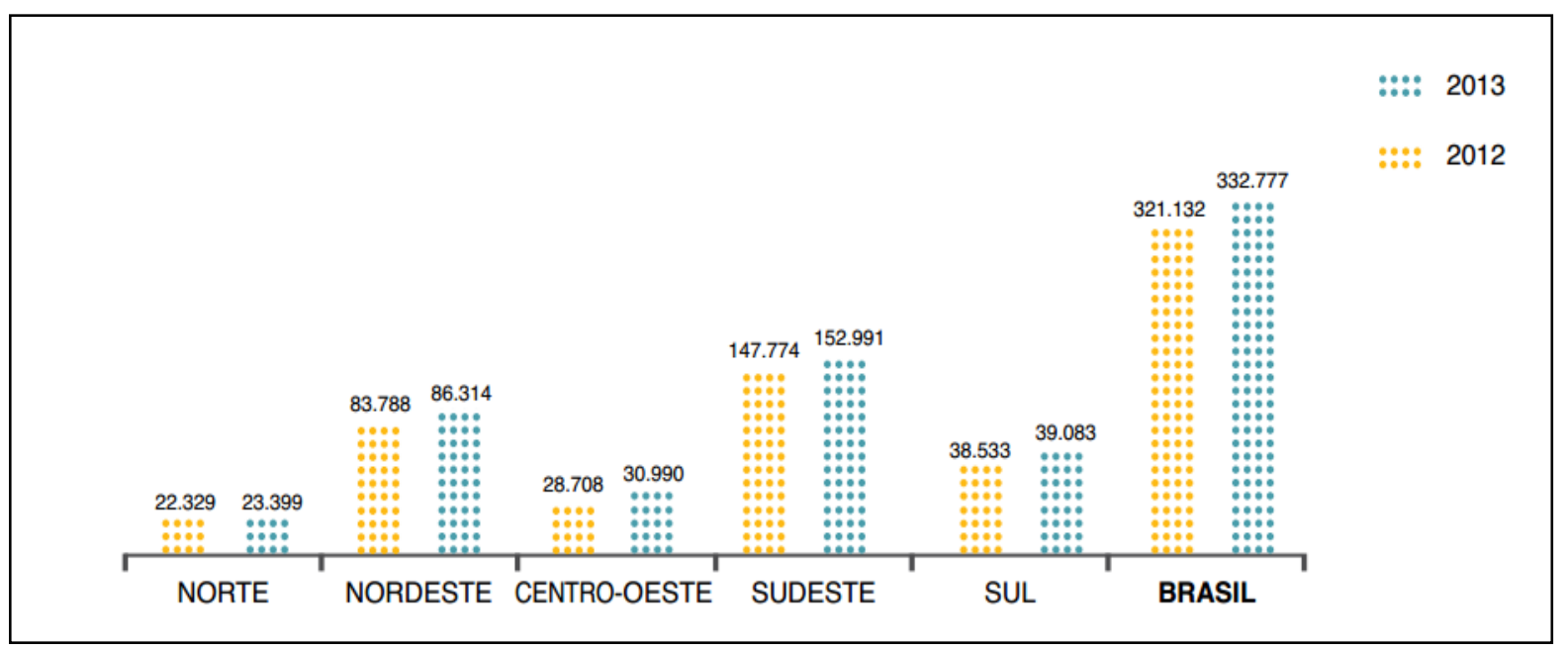

Fonte: ABRELPE (2013).

\subsubsection{A Educação Ambiental e a logística reversa}

As escolas podem e devem desenvolver projetos com vistas à conscientização ambiental. A seguir são apresentados dois exemplos de projetos que foram desenvolvidos em escolas do Estado do Rio Grande do Sul.

Na Escola Municipal Walter Jacob Bauermann (RS), está sendo realizada uma campanha em prol da sustentabilidade. A referida campanha foi implantada em conjunto com os supermercados do bairro, pontos comerciais e a empresa Suzuki Recicladora. A mesma visa conscientizar os alunos sobre o consumo consciente dos produtos e o destino correto dos resíduos plásticos que são produzidos diariamente. A fim de alcançar o objetivo proposto, estabeleceu-se como meta a construção de uma parada de ônibus ecológica, produzida com resíduos plásticos reciclados e viabilizada pela parceria dos supermercados do bairro com a Suzuki. Para pôr em prática o projeto são necessários reunir 212 mil itens, totalizando ao final 950 quilos. Os alunos, professores e a comunidade, engajaram-se na campanha, pois já haviam conseguido retirar do meio ambiente cerca de 600 quilos de lixo plástico (O Diário, 2013).

Outro exemplo foi de uma escola localizada na cidade de Novo Hamburgo (RS), que realizou uma campanha entre os seus alunos tendo como meta a coleta de sacolas plásticas. A escola coletou em torno de 30.000 sacolinhas plásticas evitando que as mesmas fossem parar em aterros 
sanitários. O Supper Rissul a fim de realizar a logística reversa destas embalagens, recebeu as mesmas e encaminhou para a reciclagem. O gerente ficou muito feliz com este resultado, pois além de contribuir com o meio ambiente, este beneficiou a escola, presenteando a mesma com dois contornos para canteiro e dois bancos produzidos a partir da reciclagem de resíduos plásticos sem valor comercial (SUPPER RISSUL,2013).

A partir do ano de 2000, a Lei no 9.974/2000 passou a estabelecer sanções administrativa, civil e penal. Esta lei é direcionada ao produtor, comerciante, importador, profissional, empregador e ainda ao usuário ou prestador de serviços, que agirem em discordância com a lei. Observase que as organizações não se contentaram apenas em cumprirem a lei, foram além, os mais diversos setores também souberam explorar as potencialidades e passaram a usufruir dos benefícios da logística reversa. Os autores Xavier e Corrêa (2013) relatam diversos casos consolidados. Dentre os quais, pode-se mencionar o recolhimento e tratamento das embalagens de pós-consumo dos produtos fitossanitários (fungicidas, inseticidas, acaricidas e herbicidas), conhecidos como agrotóxico.

$\mathrm{Na}$ indústria de eletroeletrônicos e eletrodomésticos, pode-se destacar o programa criado pela empresa Philips Brasil. No ano de 2008 a empresa lançou na cidade de Manaus um programa piloto chamado de "Ciclo Sustentável Philips". Este programa dispõe-se a coletar todos os tipos de aparelhos eletroeletrônicos e eletrodomésticos produzidos pela Philips e que os consumidores não utilizam ou não pretendem mais utilizar. Desta forma, estes produtos poderão ser encaminhados para um local ambientalmente apropriado. Entre os diversos produtos coletados, estão as TVs, aparelhos de áudio e vídeo, cafeteiras, entre outros (PHILIPS, 2014).

Como descrito por Guarnieri (2011), o processo logístico reverso também está presente na indústria automobilística. São passíveis de reuso/reciclagem, as peças ou componentes recusados nas vistorias de qualidade, embalagens utilizadas no armazenamento ou transporte, peças defeituosas devolvidas pelos clientes através de recall, entre outros. De acordo com a autora, a indústria madeireira é outro setor que se beneficia da logística reversa para melhorar a sua produtividade. As empresas do setor destinam os resíduos (serradura, cascas, aparas, refugos, efluentes líquidos) gerados para o mercado secundário ou ainda, para outras indústrias que utilizam estes resíduos como matéria-prima.

Em relação aos Resíduos Sólidos Urbanos (RSU) reciclados no Brasil, Guarnieri (2011) destaca os setores do papel, alumínio, vidro e plástico como sendo as atividades que mais reciclam os produtos de pós-consumo no país. Destes quatro setores, o resíduo mais valorizado é o alumínio, seu valor atraente certamente contribui para o alto índice de reciclagem, alcançando hoje 99\%. Por meio da pesquisa (Figura 4) realizada pela ABRELPE, pode-se ter uma visão macro da participação de cada uma das regiões no total de resíduos sólidos urbanos coletados no país no ano de 2013. 


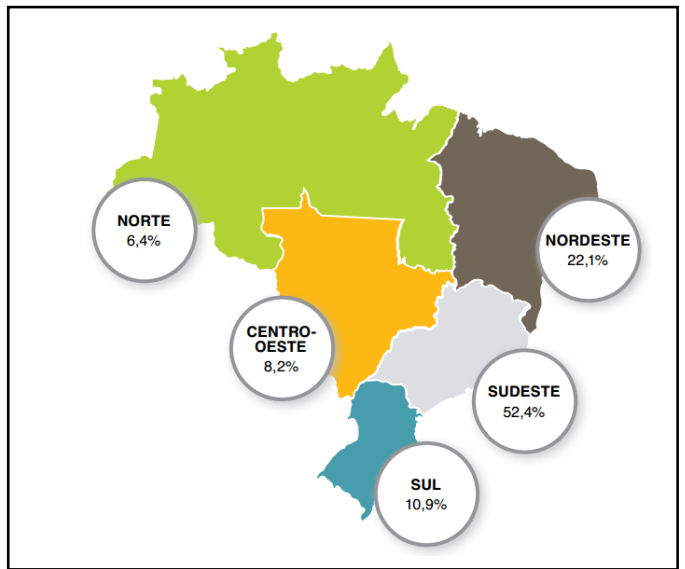

Fonte: Abrelpe (2013).

De modo geral, cada segmento de negócio abordado nesta pesquisa apresenta suas próprias peculiaridades. Percebe-se, que todos estes setores possuem regras e exigências legais específicas, tanto para o descarte, quanto para o reuso/reciclagem dos resíduos que sua cadeia produtiva gerar.

Entretanto, o referido estudo mostrou que qualquer empresa, independentemente do segmento em que atua, poderá investir em um sistema logístico reverso. Ainda que a adoção desta ferramenta exija todo um planejamento, elaboração de projeto, investimentos pesados, e paciência, pois, a obtenção de retorno será a médio e longo prazo, as organizações poderão obter vantagens competitivas significativas.

Portanto, a organização que adotar a logística reversa, seja inicialmente por força da lei, ou por questões estratégicas, se desenvolver um projeto bem estruturado, sem dúvida nenhuma, obterá vantagens econômicas e financeiras. Do ponto de vista ambiental, para esta empresa representará menor desperdício de material, consequentemente menor gasto com energia e diminuição da emissão de gases poluentes, entre outros fatores não menos importantes. Somam-se a isto, os ganhos sociais, como a geração de emprego e renda, proporcionando maior qualidade de vida a todos os envolvidos.

\section{Metodologia}

Este artigo constitui-se num ensaio teórico realizado por meio de uma pesquisa bibliográfica. Elaborada com base na leitura de livros de autores de renome na área ambiental e artigos disponíveis na internet.

Foi escrito para ser apresentado especialmente no III Congresso Internacional de Educação Ambiental promovido pela Universidade Federal de Santa Maria em parceria com o Conselho Municipal do Meio Ambiente de Panambi (RS).

\section{Conclusão}

A pesquisa bibliográfica proposta trouxe esclarecimentos acerca do surgimento desta ferramenta ambiental, a logística reversa, além de elucidar as dúvidas em relação às suas vantagens. Permitiu também conhecer e descrever diversos exemplos em que sua aplicabilidade é uma realidade.

São várias as vantagens proporcionadas pela logística reversa. A sua implantação permitirá a reutilização de materiais e/ou embalagens no ciclo de produção de novos produtos. Ou ainda, possibilitará a reciclagem ou destinação dos materiais e/ou produtos de pós-consumo que já chegaram ao fim de sua vida útil. A adoção de matéria-prima reciclada na maioria das vezes contribuirá para a economia de energia e diminuição da poluição.

Durante as leituras foi possível conhecer inúmeros segmentos e empresas que adotaram a logística reversa em seus processos produtivos e obtiveram vantagens competitivas. Também 
conheceu-se projetos realizados por escolas sobre o tema logística reversa. Destacam-se empresas gigantes do varejo, como a Coca-Cola, empresa do setor de bebidas, a PepsiCo, do setor de alimentos e bebidas e a empresa Philips, do setor de eletroeletrônicos e eletrodomésticos.

Desta forma, conclui-se que mesmo havendo um custo elevado para sua implantação, as organizações devem investir na logística reversa, não somente por obrigação legal, mas também por questões estratégicas. Pois ficou evidente que a mesma desempenha um importante papel, sendo responsável pelo fomento de ações que proporcionam ganhos para a economia, para o meio ambiente e a sociedade. Cabe ao professor abordar o tema logística reversa em sala de aula com seus alunos, pois muitos destes poderão vir a serem os futuros administradores do nosso país.

\section{Referências}

ABRELPE. Panorama dos resíduos sólidos no Brasil - 2013. Disponível em: <www.abrelpe.org.br/Panorama/panorama2013.pdf>. Acesso em: 14 set. 2014.

BELLEN, Hans Michael van. Indicadores de Sustentabilidade: uma análise comparativa. Rio de Janeiro: FGV, 2006, Ed. 2.

BRASIL. Lei n. 12.305, de 2 de agosto de 2010. Institui a Política Nacional de Resíduos Sólidos; altera a Lei n. 9.605, de 12 de fevereiro de 1998 e dá outras providências. Disponível em: $<$ www.planalto.gov.br>. Acesso em: 14 set. 2014

CMMAD - Comissão Mundial sobre Meio Ambiente e Desenvolvimento. Nosso Futuro - Comum. $2^{a}$ ed. Rio de Janeiro: Editora da Fundação Getúlio Vargas, 1991.

COCA-COLA. Coca-Cola investe R\$ 8 milhões em reciclagem. Disponível em: <cocacolabrasil.com. br/imprensa/release/coca-cola-brasil-investe-r-8-milhoes-em-reciclagem $>$. Acesso em: 18 set. 2014.

GIORDANO. S. Marketing e Meio Ambiente. In: NEVES, M. F. CASTRO, L. T. Marketing e Estratégia em Agronegócios e Desenvolvimento. São Paulo: Atlas, 2003.

GUARNIERI, Patrícia. Logística Reversa: em busca do equilíbrio econômico e ambiental. Recife: Clube de Autores, 2011.

SUPPER RISSUL, 22.04.2013. Disponível em: $<$ http://www.unisoldsustentabilidade.com.br/new/index.php/ parceiros/item/33-supper-rissul-de-novohamburgo-recebe-homenagem-de-escola-do-município>. Acesso em: 20 mar. 2015. 2003.

LEITE, P. R. Logística reversa: meio ambiente e competitividade. São Paulo: Prentice Hall,

O Diário. Escola trabalha conscientização ambiental. Disponível em: $<$ http://www.unisoldsustentabili dade.com.br/new/index.php/parceiros/item/40-escola-trabalhaconscientização-ambiental>. Acesso em: 20 mar. 2015.

PEPSICO. PepsiCo destaca ações voltadas à reciclagem e descarte correto de embalagens na Expocatadores. Disponível em: <www.pepsico.com.br/pepsico-destaca-acoes-voltadas-a-reciclagem-edescarte-correto-de-embalagens-na-expocatadores>. Acesso em: 15 set. 2014.

PHILIPS. Programa Ciclo Sustentável Philips. Disponível em: $<w w w . s u s t e n t a b i l i d a d e . p h i l i p s . c o m . b r /$ sustentavel.htm>. Acesso em: 15 set. 2014. responsabilidade-ambiental/programa-philips-ciclo-

REVISTA VIDRO ALUMÍNIO. Reciclagem de vidros automotivos. Disponível em: <www.revistavidroealuminio.com.br/reciclagem-de-vidros-automotivos/>. Acesso em: 15 set. 2014.

ROGERS, D. S. \& TIBBEN-LEMBKE, R. S. Going backwards: reverse logistics trends and practices. Reno: Universidade de Nevada, 1999. 
TADEU, Hugo Ferreira Braga et al. Logística reversa e sustentabilidade. São Paulo: Cengage Learning, 2013.

VALLE, Rogerio; Souza, Ricardo Gabbay. Logística Reversa: processo a processo. São Paulo: Atlas, 2014

XAVIER, Lúcia Helena; CORRÊA, Henrique Luiz. Sistemas de Logística Reversa: criando cadeias de suprimento sustentáveis. São Paulo: Atlas, 2013. 